Tersedia online di: http://ejournal-balitbang.kkp.go.id/index.php/JP
e-mail:jurnalpari@gmail.com
JURNAL PARI
Volume 6 Nomor 2 Desember 2020
p-ISSN: 2502-0730
e-ISSN : 2549-0133

\title{
PEMANFAATAN APLIKASI BITLY.COM DALAM DISEMINASI INFORMASI HASIL-HASIL PENELITIAN JURNAL KELAUTAN DAN PERIKANAN TERAPAN
}

\author{
Widya Indarti \\ Pustakawan Pada Perpustakaan Politeknik AUP Jakarta \\ Diterima tanggal : 13 Juli 2020 Diterima setelah perbaikan : 24 November 2020 \\ disetujui terbit : 21 Desember 2020
}

\begin{abstract}
ABSTRAK
Istilah diseminasi saat ini sudah menjadi istilah umum yang digunakan sebagai sinonim dari "penyebaran". Dengan perkembangan teknologi informasi yang semakin pesat, diseminasi dapat digunakan dalam berbagai bidang sebagai penyampaian informasi instansi/lembaga terkait misalkan dalam bidang pendidikan, penelitian, dan lain sebagainya. Adanya respon atau timbal balik dari penikmat informasi terhadap materi yang disebarluaskan oleh perpustakaan merupakan tujuan utama dari penyebarluasan informasi yang disampaikan. Dalam penyampaian diseminasi informasi harus inovatif, interaktif, dan dapat mempengaruhi pola pikir dan tindakan publik, termasuk orang yang membawa inovasi itu sendiri. Melalui makalah ini, penulis ingin berbagi mengenai bisnis online berplatform perpustakaan dengan bitly.com yang dapat dijadikan alat untuk mendiseminasi hasil-hasil penelitian yang dimiliki perpustakaan. Perpustakaan AUP Jakarta, sebagai sebuah perpustakaan khusus yang memiliki dokumen-dokumen online hasil karya civitas akademika bidang kelautan dan perikanan terapan merasa perlu menyediakan akses personal yang menghubungkan perpustakaan dengan pemustakanya sebagai wujud layanan prima.
\end{abstract}

Kata Kunci: Bisnis online; diseminasi informasi; Karya Tulis IImiah; Jurnal Kelautan dan Perikanan Terapan (JKPT)

\begin{abstract}
The term dissemination has now become a general term used as a synonym of "dissemination". With the rapid development of information technology, dissemination can be used in various fields as the delivery of information related institutions / institutions for example in the fields of Education, research and so forth. The response or reciprocity of the connoisseurs of information on the material disseminated by the library is the main objective of the dissemination of the information conveyed. In delivering information dissemination, it must be innovative, interactive, and can influence the mindset and actions of the public, including people who bring the innovation itself. Through this paper, the author wants to share about the online business with a library platform with bitly.com which can be used as a tool to disseminate research results owned by the library. The Jakarta AUP Library, as a special library that has online documents created by the academic community in the field of applied marine and fisheries, feels the need to provide personal access that connects the library with its library as the representation of user's satisfaction service.
\end{abstract}

Keywords: Online business; information dissemination; Scientific Writing; Journal of Applied Maritime and Fisheries (JKPT) 


\section{PENDAHULUAN Latar Belakang}

Perpustakaan merupakan salah satu bentuk layanan publik yang bertugas menyediakan informasi sesuai dengan kebutuhan masyarakat (dalam dunia kepustakawanan masyarakat pengguna perpustakaan disebut dengan pemustaka). Secangggih dan selengkap apapun perpustakaan tidak akan berarti tanpa pengelola yang handal, trampil dan ramah (pengelola perpustakaan dalam dunia kepustakawanan disebut dengan pustakawan). Artinya bahwa kemampuan, ketrampilan, kehandalan dan keramahan pustakawan menjadi modal dasar dalam layanan perpustakaan.

Layanan merupakan salah satu tolok ukur keberhasilan suatu perpustakaan, yang dalam undang-undang no. 43 tahun 2007 tentang Perpustakaan pada pasal 4 disebutkan bahwa Perpustakaan bertujuan memberikan layanan kepada pemustaka meningkatkan kegemaran membaca, serta memperluas wawasan dan pengetahuan untuk mencerdaskan kehidupan bangsa. Dengan demikian jelas bahwa layanan yang diberikan harus sesuai dengan kebutuhan pemustaka berlandaskan pada visi dan misi perpustakaan (SNI perpustakaan), sehingga layanan yang diberikan adalah layanan prima. Karena layanan prima menjadi salah satu alat utama dalam melaksanakan strategi untuk mempromosikan perpustakaan supaya pemustaka mau datang dan memanfaatkan perpustakaan.

Bisnis online berplatform perpustakaan, masih sangat jarang. Namun untuk berinovasi menggunakan aplikasi bisnis online bukan sesuatu yang baru di era teknologi informasi dalam hal ini menyebarluaskan kembali ilmu pengetahuan. Salah satunya adalah bitly.com yang dapat digunakan perpustakaan untuk menyebarluaskan informasi kepada pemustakanya.

Mengenal bisnis online adalah kekuatan alat di era informasi yang dapat dipelajari pustakawan dan petugas dalam menyebarluaskan informasi yang dikemas dalam bentuk standar dokumen menggunakan web-web informasi yang tersedia, sehingga kebutuhan informasi pemustaka dapat dilakukan dengan meng-klik saja dan memanajemen link-link tersebut sebagai kumpulan pengetahuan yang saling mendukung. Sehingga dalam makalah ini perlu dijelaskan mengenai pengertian pemanfatan aplikasi bisnis online bitly.com; pengertian diseminasi informasi dengan platform perpustakaan. Studi kasus telah dilakukan penulis juga untuk berinisiasi melakukan diseminasi informasi hasil-hasil penelitian yang dipublikasikan Jurnal Kelautan dan Perikanan
Terapan (JKPT) yang di terbitkan Politeknik AUP Jakarta memanfaatkan akun non bayar bitly.com.

\section{BATASAN MASALAH}

Dalam makalah ini, penulis perlu membatasi masalah-masalah yang akan dibahas dalam makalah ini, yaitu, bagaimana pemanfaatan aplikasi bitly.com dalam diseminasi Informasi hasil-hasil Penelitian Jurnal Kelautan dan Perikanan Terapan (JKPT)

\section{TUJUAN PENULISAN MAKALAH}

Dalam makalah ini, penulis bertujuan membahas bagaimana pemanfaatan aplikasi bitly.com dalam diseminasi Informasi hasil-hasil Penelitian Jurnal Kelautan dan Perikanan Terapan (JKPT)

\section{METODE}

Metode yang digunakan pada makalah ini adalah melakukan pemanfaatan situs bisnis oline bitly.com sebagai alat diseminasi untuk mentransformasikan akses ke hasil-hasil penelitian bidang kelautan dan perikanan terapan / JKPT. Melakukan studi terperinci tentang bitly.com dan studi pustaka mengenai diseminasi informasi yang dilakukan perpustakaan sebagai wujud layanan prima.

\section{PEMBAHASAN \\ Pengertian Aplikasi Bisnis bitly.com}

Pengertian bitly.com: bitly adalah aplikasi layanan bisnis online yang mentransformasikan berbagai link sebagai kekuatan alat yang mendukung tim penjual dan pembelinya. Dukungan Layanan bisnis online yang diberikan oleh bitly. Melalui bitly pengguna atau user yang akan dapat memanfaatkan fasilitas sebagai berikut:

\section{Melakukan Custom Back-Half}

Agar dokumen perpustakaan yang memiliki link cukup Panjang, maka dapat diidentifikasi dengan menyederhanakan alamat url nya. Hasil-hasil custom tersebut, misalnya bitly/2WqXQBE

Alamat asal, yaitu http: e journal-balitbang.kkp.go.id/index php/jkpt/ article/view/8001/6301

2. Melakukan manajemen link yang dimiliki user Manajemen link yang dapat dilakukan berupa:

a. Link Creation atau penciptaan link

b. Link click atau metode akses link dengan berbagai alat komunikasi apps

c. Link tags atau menciptakan tag-tag terkait link

d. Bulk Link Tagging atau menciptakan tag-tag dari bulk link 
e. Link Filtering atau menyaring link

3. Melakukan Manajemen Kampanye

Manajemen kampanye yang dilakukan adalah dengan social posting pada twitter dan face book, dapat juga medsos lainnya yang digunakan, melalui manajemen link

4. Mampu menampilkan data dan analisis

Setiap dokumen online yang telah di custom dilengkapi data statistik pemakaian ketersebarannya dan keterkaitannya (di klik) antara perpustakaan dan user, menampilkan sejarah link dan laporannya.

5. Platform akses yang standar

Untuk mengakses Kembali dokumen perpustakaan yang telah disebarluaskan, tersedia web browser, mobile app, API v4, Saluran - akses web tertentu.

6. Kesuksesan Pelanggan

Pelanggan memahami pengetahuan dasar diseminasi dokumen online perpustakaan, dimana sumber ini disediakan oleh bit.ly pada menu "How to Use"

\section{Pengertian Diseminasi}

Seorang pustakawan bernama Lasa HS dalam Arif Nurdiansah (2013), mengatakan bahwa perpustakaan tidak hanya sebagai Lembaga yang mengumpul, mengelola, menyimpan dan melestarikan bahan pustaka, tetapi lebih kepada penyebaran informasi atau disebut diseminasi informasi. Jika penyebaran informasi diutamakan dengan dibantu teknologi yang memungkinkan pustakawan menginformasikan koleksinya kepada pengguna maka akan sangat membantu pencarian koleksi yang dibutuhkan. Saat ini teknologi internet dapat melakukan penyebaran dokumen digital termanajemen dalam jumlah yang tanpa batas. Diseminasi menurut Sulistyo Basuki dalam Arif Nurdiansah (2013) sangat erat kaitannya dengan istilah publisitas dan promosi sehingga sering disebutkan sebagai bagian dari strategi promosi.

Diseminasi adalah suatu kegiatan penyebaran informasi yang ditujukan kepada kelompok target atau individu agar mereka memperoleh informasi, timbul kesadaran, menerima, mengubah perilaku sasaran, dan akhirnya mereka mampu memanfaatkan informasi tersebut. Perubahan yang diharapkan dari kegiatan diseminasi adalah akan terjadi pada aspek kognitif (pengetahuan - P), afektif (sikap-S) dan psikomotorik (keterampilan-K). Perubahan tersebut menuju kearah yang sesuai dengan konsep dan cara yang benar atau seharusnya. Diseminasi juga biasa disebut sebagai proses penyebaran inovasi yang direncanakan, diarahkan, dan dikelola. Sehingga terjadi saling tukar informasi dan akhirnya terjadi kesamaan pendapat tentang inovasi tersebut.

Dengan demikian dapat disimpulkan diseminasi merupakan penyebaran inovasi yang disusun dan disebarkan dengan metode perencanaan yang matang serta pandangan jauh ke depan baik melalui diskusi atau forum lainnnya yang sengaja diprogramkan, sehingga terdapat kesepakatan untuk melaksanakan inovasi.

\section{Pelayanan Prima Perpustakaan}

Kamus Besar Bahasa Indonesia menjelaskan bahwa yang dimaksud dengan pelayanan adalah sebagai usaha melayani kebutuhan orang lain. Menurut Barata (2012) bahwa suatu pelayanan akan terbentuk karena adanya proses pemberian layanan tertentu dari pihak penyedia layanan kepada pihak yang dilayani. Terdapat 3 (tiga) pihak pendukung proses layanan, yaitu (1) pihak penyedia layanan, (2) pihak yang menerima layanan, dan (3) jenis atau bentuk layanan. Layanan dapat terjadi antara seorang dengan seorang, seorang dengan kelompok, kelompok dengan seorang, atau orang-orang dalam organisasi baik dilakukan atas dasar sukarela atau komersial. Dalam hal ini jelas terjadinya interaksi yang saling mendukung dalam kegiatan layanan.

UU No. 43 tahun 2007 tentang Perpustakaan pasal 4 menyebutkan bahwa Perpustakaan bertujuan memberikan layanan kepada pemustaka meningkatkan kegemaran membaca, serta memperluas wawasan dan pengetahuan untuk mencerdaskan kehidupan bangsa, yang terjabarkan pada bab $V$ pasal 14 sebagai berikut :

(1) Layanan perpustakaan dilakukan secara prima dan berorientasi bagi kepentingan pemustaka.

(2) Setiap perpustakaan menerapkan tata cara layanan perpustakaan berdasarkan standar nasional perpustakaan.

(3) Setiap perpustakaan mengembangkan layanan perpustakaan sesuai dengan kemajuan teknologi informasi dan komunikasi.

(4) Layanan perpustakaan sebagaimana dimaksud pada ayat (1) dikembangkan melalui pemanfaatan sumber daya perpustakaan untuk memenuhi kebutuhan pemustaka.

(5) Layanan perpustakaan diselenggarakan sesuai dengan standar nasional perpustakaan untuk mengoptimalkan pelayanan kepada pemustaka.

(6) Layanan perpustakaan terpadu diwujudkan melalui kerja sama antar perpustakaan.

(7) Layanan perpustakaan secara terpadu sebagaimana dimaksud pada ayat (6) dilaksanakan melalui jejaring telematika. 
Dengan demikian jelas bahwa layanan prima yang berorentasi pada user minded atau user oriented akan dapat terwujud dengan sikap dan karakter humanis serta professional dari pustakawan.

Layanan prima merupakan upaya perusahaan/ organisasi memberikan layanan terbaiknya sebagai wujud kepedulian kepada pelanggan (Barata, 2012). Sehingga layanan prima menjadi salah satu alat utama dalam melaksanakan strategi untuk mempromosikan perpustakaan supaya pemustaka mau datang dan memanfaatkan perpustakaan. Pada dasarnya layanan prima bertujuan untuk memuaskan pemustaka dengan tidak harus mengorbankan harga diri atau citra diri melainkan mewujudkan manfaat terbaik bagi semua pihak, yaitu dengan mengembangkan konsep triple-win customer service. Konsep triple-win customer service adalah solusi terbaik untuk kemenangan dan keuntungan semua pihak.

Perlu menyatukan persepsi antara pustakawan, pemustaka dan perpustakaan. Sebagai lembaga induk penyedia informasi. Konsep interaksi yang terjadi di dunia kepustakawanan dapat dijabarkan dengan gambar berikut :

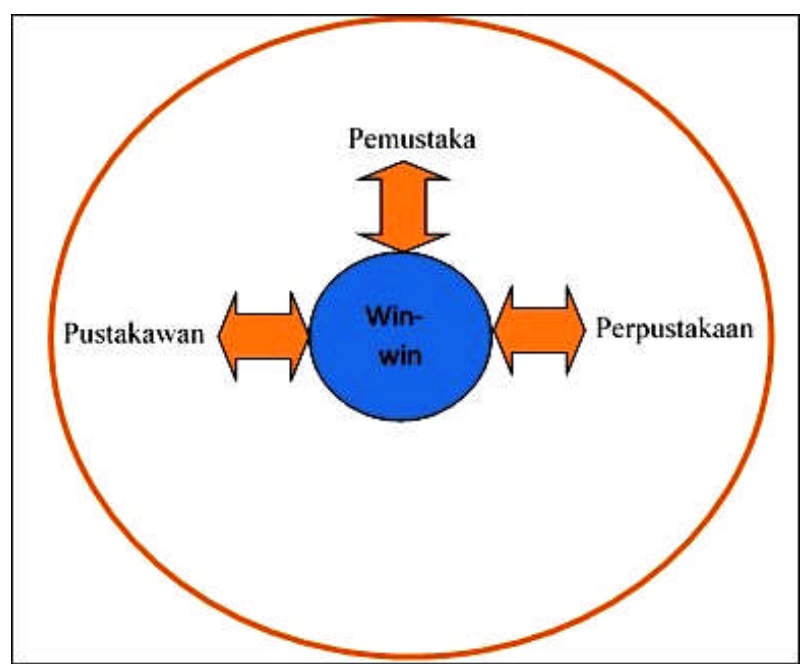

Konsep triple-win customer service yang digambarkan penulis diatas semakin memperjelas bahwa sebenarnya ketiga komponen pendukung layanan memiliki peran dan fungsi yang sama, saling bergantung dan mendukung dalam kegiatan proses layanan khususnya di perpustakaan.

\section{Faktor-Faktor Layanan Prima}

Barata (2012) dalam bukunya Dasar-Dasar Pelayanan Prima telah mengemukakan enam (6) factor A sebagai konsep mengembangkan layanan prima yaitu :
1. Ability, adalah pengetahuan dan keterampilan tertentu yang mutlak diperlukan untuk menunjang program layanan prima, yang meliputi kemampuan dalam bidang kerja yang ditekuni, melaksanakan komunikasi yang efektif, mengembangkan motivasi, dan menggunakan public realtions sebgai intrumen dalam membina hubungan ke dalam dan luar perpustakaan.

2. Attitude, adalah perilaku atau perangai yang harus ditonjolkan ketika menghadapi pemustaka.

3. Apperance adalah penampilan seseorang baik yang bersifat fisik dan non fisik, yang mampu merefleksikan kepercayaan diri dan kredibilitas dari pihak lain

4. Attention, adalah kependulian penuh terhadap pelanggan, baik yang berkaitan dengan perhatian akan kebutuhan dan keinginan pelnggan maupun pemahaman atas saran dan kritiknya.

5. Action, adalah berbagai kegiatan nyata yang harus dilakukan dalam memberikan layanan kepada pemustaka.dan

6. Accountability adalah suatu sikap keberpihakan kepada pemustaka sebagai wujud kependulian untuk menghindari atau meminimalkan kerugian atau ketidakpuasan pemustaka.

Aplikasi dalam memberikan layanan prima pada hakekatnya harus mengandung faktor-faktor di atas yang dapat dilakukan diberbagai kegiatan layanan perpustakaan berawal dari layanan adminitrasi, sirkulasi, referensi, penelusuran dan sebagainya. Konsep tersebut menjadi pijakan agar layanan prima diberikan oleh pustakawan kepada pemustaka.

\section{Diseminasi Hasil-Hasil Penelitian Bidang Kelautan dan Perikanan Terapan dengan memanfaatkan akun non bayar dengan nama Perpustakaan Poltek AUP Jakarta}

Diseminasi Hasil-Hasil Penelitian Bidang Kelautan dan Perikanan Terapan dengan memanfaatkan akun non bayar dengan nama Perpustakaan Poltek AUP Jakarta telah berjalan selama dua minggu, dengan tampilan sebagai berikut:

Diseminasi Hasil-Hasil Penelitian Bidang Kelautan dan Perikanan Terapan dengan memanfaatkan akun non bayar dengan nama Perpustakaan Poltek AUP Jakarta telah berjalan selama dua minggu dengan 14 link yang didiseminasikan, 61 klik sebagai respon.

Dalam pencarian ini diketahui bahwa Kultur perilaku pencarian informasi di internet terdapat dua hal yaitu search \& social (Rossmann et al. 2015). yaitu, pencari informasi mencari informasi yang dibutuhkan melalui search engine dan membaginya 
melalui sosial media. Komunitas online terbentuk karena kesamaan minat, hobi dan ketertarikan.

Hal ini mendorong sebuah perusahaan untuk mengembangkan strategi baru membangun loyalitas (engagement) dengan pelanggan melalui sosial media Sesuai gambaran tersebut, maka bisa dikatakan sosial media memiliki kekuatan untuk membangun persepsi penggunanya apabila dimanfaatkan secara optimal.
Pada diseminasi informasi menggunakan bit.ly ini, pustakawan melihat repetisi atau pengulangan akses dokumen digital (klik) yang dilakukan pengguna sebagai indikasi kesamaan kekhususan kebutuhan pengguna perpustakaan Politenik AUP Jakarta. Dalam waktu yang sangat cepat yaitu 2 minggu saja, aktivitas klik dokumen digital telah bertambah dari 42 klik menjadi 61 klik.

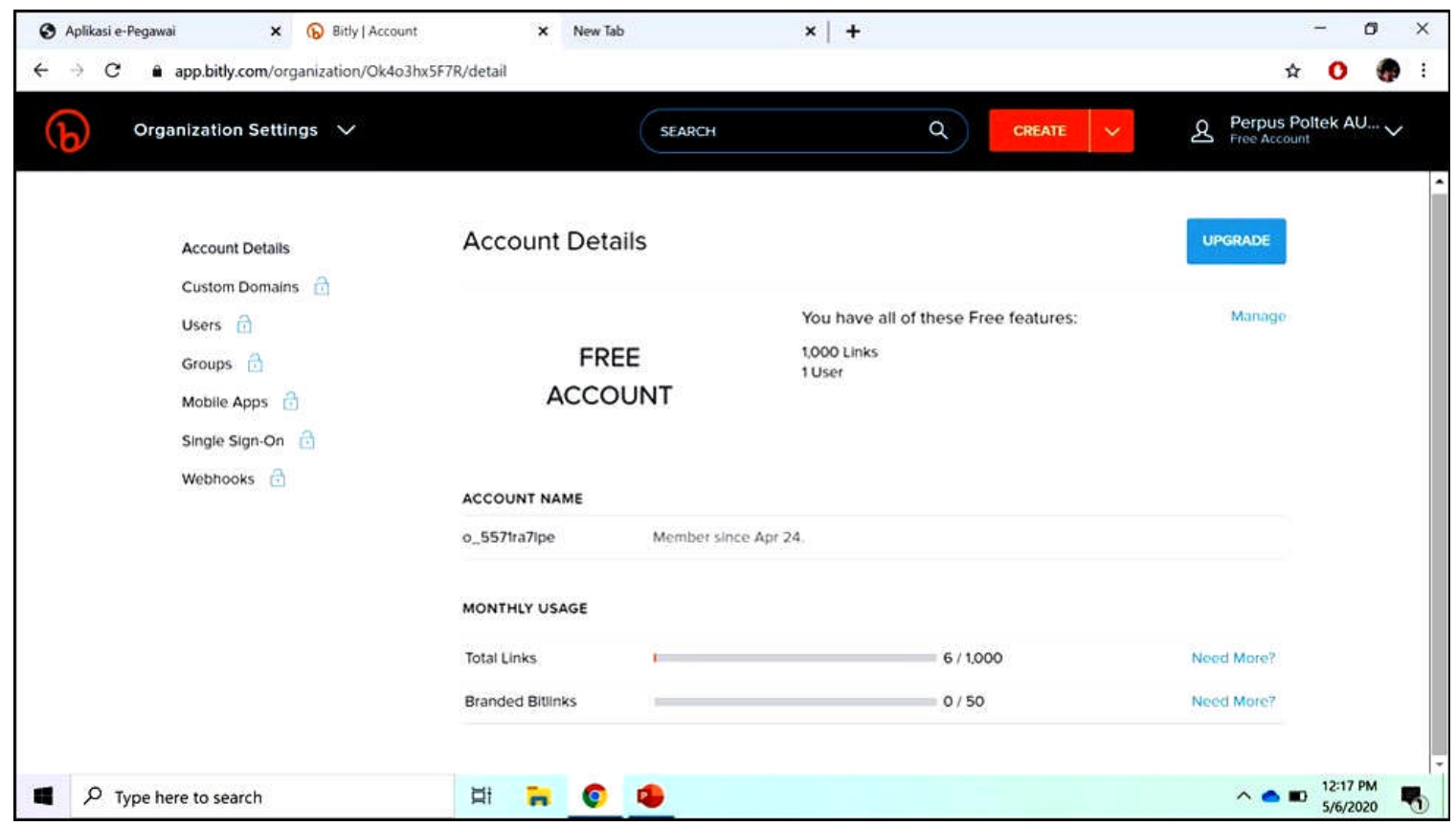

Gambar 1. Tampilan hasil registrasi akun.

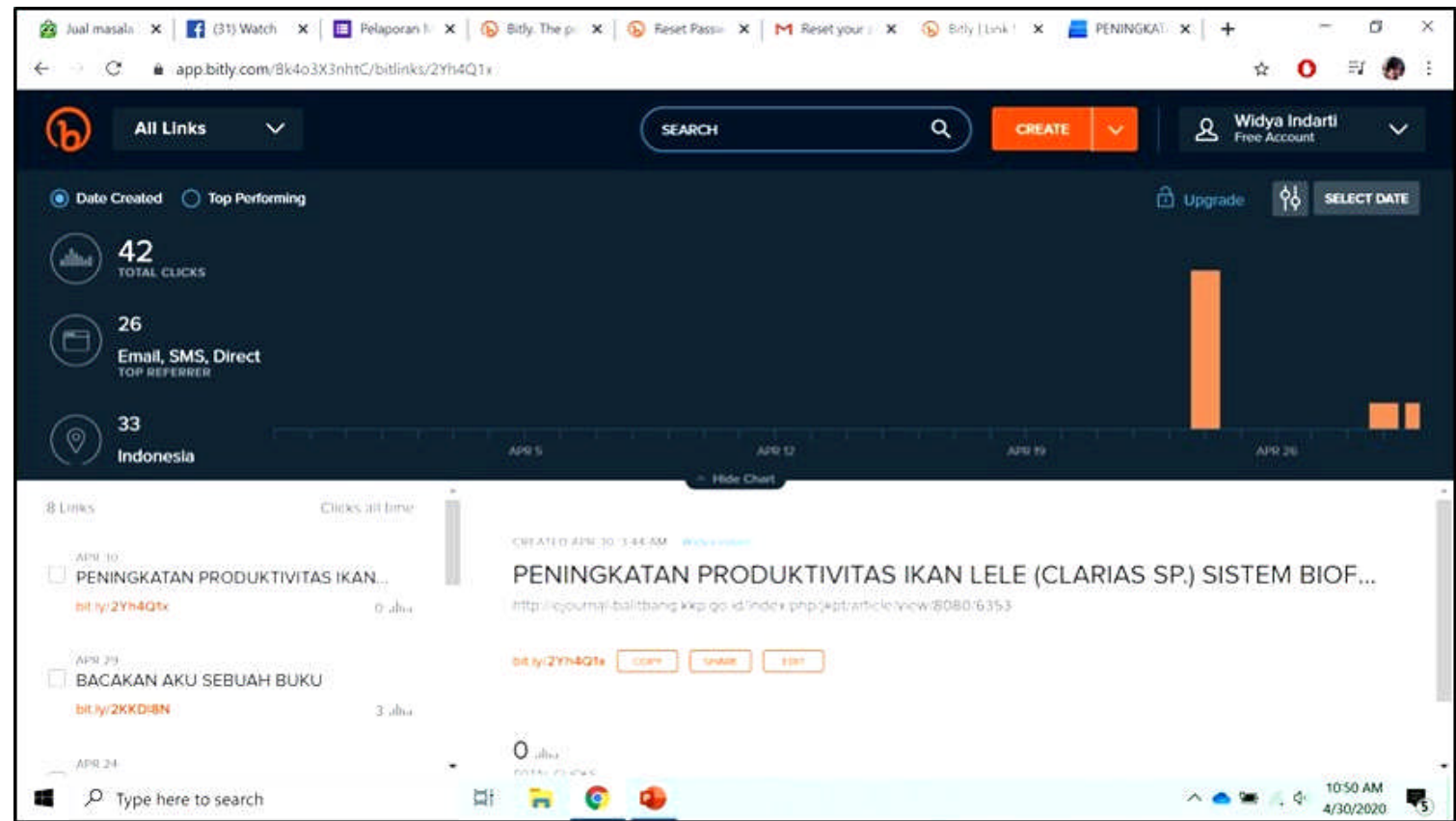

Gambar 2. Pemanfaatan Akun bitly.com. 


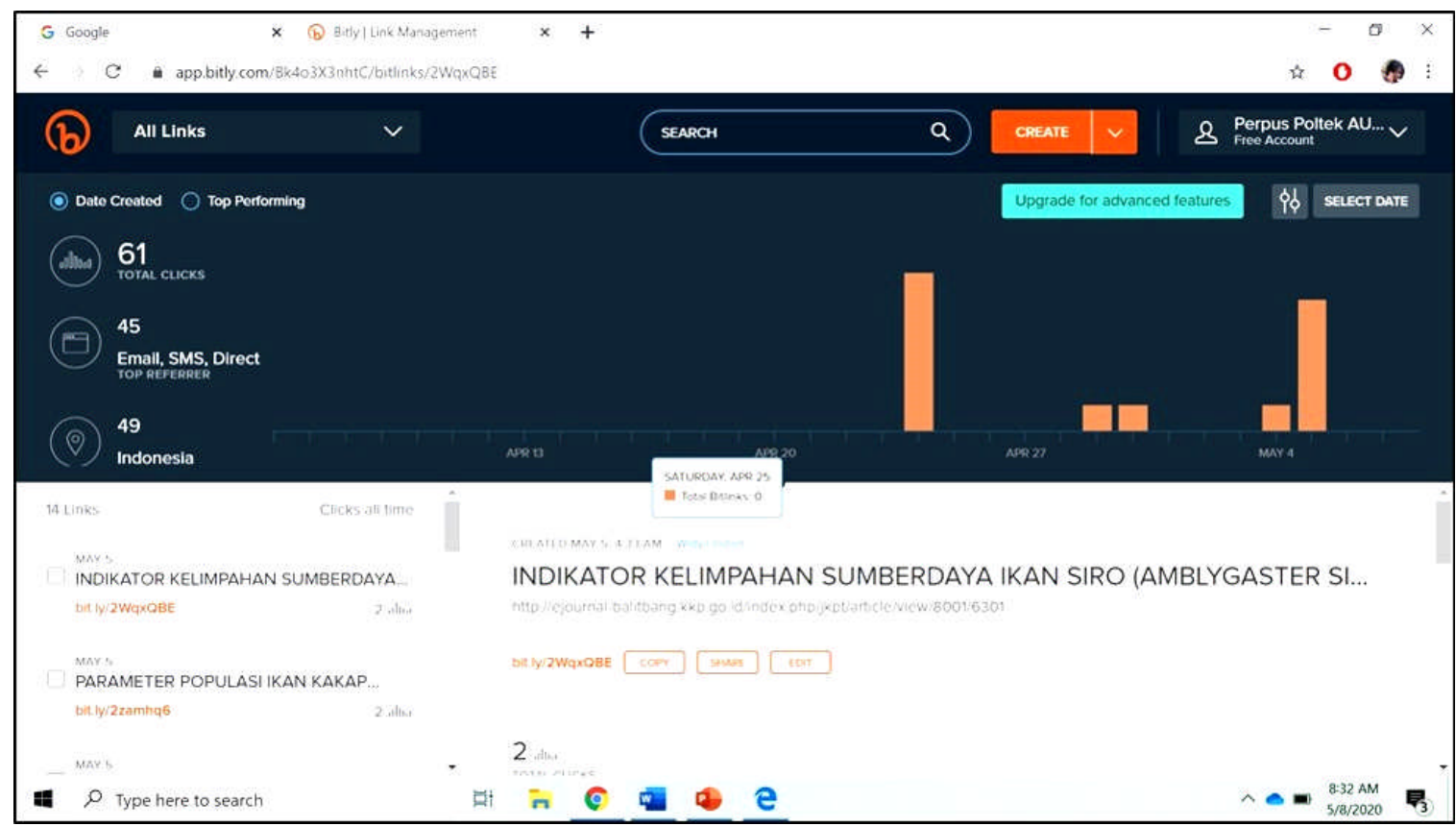

Gambar 3. Konsistensi user perpustakaan memanfaatkan akses yang diberikan perpustakaan.

\section{KESIMPULAN}

Melalui penulisan makalah ini, diketahui bahwa:

1. Diseminasi Hasil-Hasil Penelitian Bidang Kelautan dan Perikanan Terapan dengan memanfaatkan akun non bayar dengan nama Perpustakaan Poltek AUP Jakarta telah berjalan selama dua minggu dengan 14 link yang didiseminasikan, 61 klik sebagai respon

2. Jika penyebaran informasi diutamakan dengan dibantu teknologi internet yang memungkinkan pustakawan menginformasikan koleksinya kepada pengguna maka akan sangat membantu pencarian koleksi yang dibutuhkan

\section{DAFTAR PUSTAKA}

Chen, Dora \& Chu, Samuel \& Xu, Shuqin. (2012). How do libraries use social networking sites to interact with users. Proceedings of the American Society for Information Science and Technology. 49. 10.1002/meet.14504901085.

Farida, Ida \& Tjakraatmadja, Jann \& Firman, Aries. (2015). A conceptual model of Open Access Institutional Repository in Indonesia academic libraries. Library Management. 36. 168-181. 10.1108/ LM-03-2014-0038.
Lamont, Lisa \& Nielsen, Jordan. (2015). Calculating value: a digital library's social media campaign. The Bottom Line. 28. 106-111. 10.1108/BL-07-20150010.

Nurdiansah, Arif.(2013). Efektifitas Diseminasi Informasi di Perpustakaan Kemitraan Bagi Pembaruan Tata Pemerintahan Jakarta Menurut Persepsi Pengguna:Skripsi. Yogyakarta: Program Studi Ilmu Perpustakaan, Fakultas Adab dan Ilmu Budaya, UIN Sunan Kalijaga.

Rossmann, Doralyn \& Young, Scott. (2015). Social media optimization: making library content shareable and engaging. Library Hi Tech. 33. 526-544. 10.1108/LHT-05-2015-0053.

Wijayanti, Nova \& Yulianti, Rita \& Wijaya, Bagus. (2019). Pengaruh sosial media terhadap user engagement pada akun facebook perpustakaan perguruan tinggi. Berkala Ilmu Perpustakaan dan Informasi. 15. 48. 10.22146/bip.27506. 